\title{
Expressão do colágeno I em carcinomas epidermóides da cavidade oral
}

\section{Collagen type I expression in squamous cell carcinoma of the oral cavity}

\author{
Gabriela Botelho Martins* \\ Sílvia Regina de Almeida Reis** \\ Tânia Maria Correia Silva***
}

\begin{abstract}
RESUMO: A matriz extracelular no carcinoma epidermóide da cavidade oral sofre modificações qualitativas e quantitativas durante a sua progressão. Estas alterações parecem possibilitar os processos de invasão e metástase que caracterizam as neoplasias malignas e são mais evidentes na interface tumor-hospedeiro. No nosso estudo, 23 biópsias incisionais de carcinomas epidermóides de diversas localizacoones da cavidade oral foram classificadas segundo o sistema de graduação histológica preconizado por Anneroth et al. ${ }^{1}$ (1987). Foram utilizadas as colorações pela H. E. e a do tipo picrosirius, específica para colágeno. A expressão imuno-histoquímica do colágeno tipo I foi analisada em lesões com diferentes escores histológicos de malignidade. Pôde-se concluir que o colágeno apresenta diferentes padrões morfológicos, histoquímicos e imuno-histoquímicos em lesões com altos e baixos escores de malignidade.
\end{abstract}

DESCRITORES: Colágeno; Carcinoma de células escamosas; Cavidade oral.

\begin{abstract}
An analysis of the extracellular matrix at the invasive front of squamous cell carcinoma of the oral cavity may improve the understanding of tumour cell matrix interactions during malignancy growth. Alterations in collagen I expression may influence cellular invasion and metastasis. In this work, 23 cases of squamous cell carcinoma were submitted to the Anneroth's malignancy grading system ${ }^{1}$. H. E. and sirius red staining were used. Immunohistochemical expression of collagen type I protein was observed in different malignancy scores. As a result, it was observed that the extracellular matrix in squamous cell carcinoma of the oral cavity shows different patterns of collagen I expression in low and high scores of malignancy.

DESCRIPTORS: Collagen; Squamous cell carcinoma; Oral cavity.
\end{abstract}

\section{INTRODUÇÃO}

O câncer de boca corresponde a aproximadamente 3 a 4\% de todas as neoplasias malignas, sendo que mais de $90 \%$ desses tumores representam o carcinoma epidermóide ${ }^{16,19,22}$.

Lingua e assoalho de boca representam os locais mais comuns do câncer de boca, quando o lábio não é considerado, sendo mais incidente em homens acima dos 40 anos de idade ${ }^{15,16}$. O prognóstico desta patologia depende de fatores como fase de detecção da lesão, estadiamento clínico e graduação histológica $^{10}$. Os altos índices de recorrência e metástase são fatores importantes que devem ser considerados, uma vez que influenciam diretamente na sobrevida do paciente ${ }^{6,14}$.

Durante a invasão tumoral, a organização e a composição da matriz extracelular parecem sofrer algumas modificações qualitativas e quantitativas.
A análise desta complexa estrutura na frente de invasão do carcinoma epidermóide da cavidade bucal pode auxiliar no entendimento das interações entre as células tumorais e a matriz ${ }^{12}$.

Os colágenos são uma família de proteínas altamente características, encontradas em todos os animais multicelulares ${ }^{7}$. É o componente em maior quantidade de todas as matrizes extracelulares, sendo o principal produto dos fibroblastos ${ }^{22}$.

Durante o crescimento neoplásico, pode ocorrer um aumento na deposição de colágeno, principalmente dos tipos I e III, o que caracteriza a reação desmoplástica do estroma ${ }^{2}$. Este fenômeno, juntamente com a resposta imune e a angiogênese, constituem as principais respostas do hospedeiro em relação à presença de células neoplásicas ${ }^{18}$. Nos carcinomas epidermóides de mama, ovários e trato gastrointestinal, a análise do colágeno no es-

\footnotetext{
*Professora Assistente do Curso de Odontologia; ***Professora Assistente da Faculdade de Medicina - Fundação para o Desenvolvimento das Ciências (Bahia).

** Professora Adjunta do Departamento de Diagnóstico e Terapêutica da Faculdade de Odontologia da Universidade Federal da Bahia.
} 
Martins GB, Reis SR de A, Silva TMC. Expressão do colágeno I em carcinomas epidermóides da cavidade oral. Pesqui Odontol Bras 2003;17(1):82-8.

troma tumoral tem sido um valioso instrumento no prognóstico dessas lesões ${ }^{18}$.

Este estudo descritivo se propõe a uma análise morfológica, histoquímica e imuno-histoquímica da matriz colagênica de carcinoma epidermóide da cavidade oral de diferentes escores histológicos de malignidade.

\section{MATERIAL E MÉTODOS}

Foram utilizados para esta pesquisa, 23 casos de carcinomas epidermóides da cavidade oral obtidos através de biópsias incisionais de pacientes com indicação prévia das mesmas para confirmação de diagnóstico da patologia e que autorizaram o procedimento através de consentimento livre e esclarecido.

O material destinado à histologia foi fixado em formol tamponado (tampão fosfato, $\mathrm{pH} 7,4$ ), seguiu rotina histológica, com posterior inclusão em parafina. As secções foram submetidas aos seguintes métodos de coloração: hematoxilina-eosina (H. E.) e vermelho sirius (picrosirius), específico para pesquisa de colágeno ${ }^{11,21}$.

Foi utilizada para graduação histológica a classificação de tumores malignos indicada por Anneroth et al. ${ }^{1}$ (1987), que consiste da avaliação de seis características morfológicas na frente de invasão tumoral: grau de queratinização, pleomorfismo nuclear, número de mitoses, padrão de invasão, estágio de invasão e infiltração linfoplasmocitária. O parâmetro estágio de invasão foi omitido por tratar-se de biópsias incisionais de carcinomas epidermóides de boca. São considerados escores baixos os valores entre 1,0 e 2,5 e escores altos os valores entre 2,6 e 4,0.

Para realização da imuno-histoquímica, foram realizados cortes de tecido de $4 \mu \mathrm{m}$ de espessura colocados em lâminas de vidro previamente preparadas com poli-L-lisina. O método de imunomarcação utilizado foi da estreptavidina-biotina peroxidase.

Os cortes histológicos foram submetidos a desparafinização em banhos seqüenciais de xilol, acetona, álcool (absoluto, 95\%, 70\%, 50\%, 30\%) e água destilada em temperatura ambiente. Em seguida, submetidos à recuperação antigênica em "steamer" com tampão EDTA $\left(\mathrm{pH} 8,0 / 95^{\circ} \mathrm{C}\right)$ por 20 minutos com posterior bloqueio das ligações inespecíficas (leite Molico a 10\%) e então incubados "overnight" a $4^{\circ} \mathrm{C}$ com o anticorpo primário policlonal anticolágeno I (Southern Biotechnology Associates, Inc.) na diluição de 1:50. O anticorpo secundário foi utilizado segundo as orientações do kit LSAB-Peroxidase (DAKO Corporation, EUA) e a re- velação realizada através do diaminobenzidina com peróxido de hidrogênio a 30\%. As lâminas foram contracoradas com hematoxilina de Gill e montadas com bálsamo do Canadá e lamínula para avaliação qualitativa (modificado de Mineta et al. $\left.{ }^{17}, 1999\right)$.

Como controles positivos foram utilizados cortes de gengiva sadia removidos por indicação cirúrgica prévia e, como controles negativos, os mesmos tecidos, sendo suprimido da reação o anticorpo primário.

Após classificação histológica de malignidade das secções coradas pela H. E., os cortes corados pelo picrosirius foram analisados com o objetivo de se estudar a qualidade da matriz colagênica. As lâminas obtidas pelas reações imuno-histoquímicas para o anticorpo anticolágeno I foram analisadas de forma qualitativa, a fim de possibilitar um estudo descritivo das alterações observadas na matriz colagênica dos carcinomas epidermóides estudados. Para a análise do padrão de marcação seguiu-se os critérios previamente estabelecidos por Harada et al. ${ }^{8}$ (1994). Todos os cortes de tecidos foram analisados por um único patologista com experiência no estudo de carcinomas epidermóides da cavidade oral.

\section{RESULTADOS \\ Aspectos histopatológicos}

Os escores atribuídos a cada tumor estão demonstrados na Tabela 1. Dos 23 casos estudados, $14(60,9 \%)$ exibiram baixos escores de malignidade e 9 casos $(39,1 \%)$ obtiveram altos escores de malignidade.

\section{Lesões com baixos escores de malignidade}

Os cortes histológicos corados pela H. E. analisados ao microscópio de luz exibiram proliferação de células epiteliais malignas, com graus variáveis de ceratinização, predominando lesões moderadamente ceratinizadas. Apenas dois casos analisados mostravam ausência completa de ceratinização.

A análise do pleomorfismo nuclear neste grupo de lesões demonstrou que 7 dos 14 casos estudados $(50 \%)$ apresentavam grau moderado de células com núcleos pleomórficos. Observando-se o parâmetro número de mitoses notou-se que somente uma lesão mostrou ocorrência de mais de 5 mitoses por campo examinado, havendo predomínio de lesões com 2-3 mitoses por campo (50\%).

Quando a frente de invasão foi examinada notou-se predomínio de 10 casos $(71,4 \%)$ apresentando grandes áreas tumorais, com bordos bem 
Martins GB, Reis SR de A, Silva TMC. Expressão do colágeno I em carcinomas epidermóides da cavidade oral. Pesqui Odontol Bras 2003;17(1):82-8.

TABELA 1 - Distribuição dos parâmetros histológicos baseados no sistema de graduação histológica de Anneroth et al. ${ }^{1}$ (1987) modificada para carcinomas epidermóides da cavidade oral.

\begin{tabular}{|c|c|c|c|c|c|c|}
\hline Caso & $\begin{array}{c}\text { Grau de } \\
\text { ceratinização }\end{array}$ & $\begin{array}{c}\text { Grau de pleomorfismo } \\
\text { nuclear }\end{array}$ & $\begin{array}{c}\text { Grau de número } \\
\text { de mitoses }\end{array}$ & $\begin{array}{l}\text { Grau de padrão } \\
\text { de invasão }\end{array}$ & $\begin{array}{l}\text { Grau de infiltrado } \\
\text { inflamatório }\end{array}$ & Escore total \\
\hline 1 & 2 & 2 & 2 & 2 & 1 & 1,8 \\
\hline 2 & 3 & 2 & 2 & 1 & 2 & 2,0 \\
\hline 3 & 2 & 2 & 2 & 1 & 2 & 1,8 \\
\hline 4 & 2 & 2 & 2 & 3 & 3 & 2,4 \\
\hline 5 & 3 & 2 & 2 & 1 & 2 & 2,0 \\
\hline 6 & 1 & 3 & 1 & 1 & 3 & 1,8 \\
\hline 7 & 2 & 1 & 2 & 2 & 1 & 1,6 \\
\hline 8 & 4 & 1 & 1 & 1 & 3 & 2,0 \\
\hline 9 & 1 & 1 & 1 & 3 & 3 & 1,8 \\
\hline 10 & 1 & 3 & 4 & 1 & 2 & 2,2 \\
\hline 11 & 2 & 2 & 2 & 1 & 1 & 1,6 \\
\hline 12 & 2 & 3 & 1 & 1 & 3 & 2,0 \\
\hline 13 & 4 & 2 & 3 & 1 & 2 & 2,4 \\
\hline 14 & 2 & 1 & 1 & 1 & 4 & 1,8 \\
\hline 15 & 3 & 3 & 3 & 4 & 3 & 3,2 \\
\hline 16 & 3 & 3 & 2 & 1 & 4 & 2,6 \\
\hline 17 & 4 & 3 & 2 & 3 & 3 & 3,0 \\
\hline 18 & 4 & 3 & 2 & 1 & 3 & 2,6 \\
\hline 19 & 3 & 4 & 1 & 3 & 3 & 2,8 \\
\hline 20 & 3 & 4 & 4 & 1 & 3 & 3,0 \\
\hline 21 & 4 & 2 & 1 & 4 & 3 & 2,8 \\
\hline 22 & 4 & 4 & 2 & 4 & 1 & 3,0 \\
\hline 23 & 4 & 4 & 4 & 1 & 1 & 2,8 \\
\hline
\end{tabular}

delimitados (Figura 1), onde as células neoplásicas se mantinham unidas por junções celulares. Contudo, diferenças foram constatadas em 4 casos $(28,5 \%)$ quando se observou padrão de invasão mais agressivo, caracterizado, principalmente por lesões com grande contingente de células malignas formando pequenos cordões ou ilhotas, que infiltravam mais profundamente o tecido conjuntivo (Figura 2). O infiltrado inflamatório neste grupo de lesões variou de moderado a intenso e em apenas um caso observou-se ausência de células mononucleares. A matriz conjuntiva colagênica, quando vista nas secções coradas pelo picrosirius, foi abundante na maioria dos casos estudados. Próximo à frente de invasão, o colágeno esboçava um aspecto organizado, com fibras dispostas paralela- mente e circundando as ilhas de células tumorais (Figura 3).

\section{Lesões com altos escores de malignidade}

A análise ao microscópio de luz das 9 lesões cujos cortes histológicos foram diagnosticados como carcinoma epidermóide com altos escores de malignidade revelou pela coloração da H. E. neoplasias constituídas por um grande número de células epiteliais pleomórficas, com núcleos de tamanhos variados e hipercromáticos. Embora este parâmetro histológico fosse, neste grupo de lesões, mais acentuado, tanto qualitativa quanto quantitativamente, o número de mitoses na quase maioria dos casos analisados foi considerado moderado, perfazendo 2 a 3 mitoses por campo examinado. Somente 2 ca- 


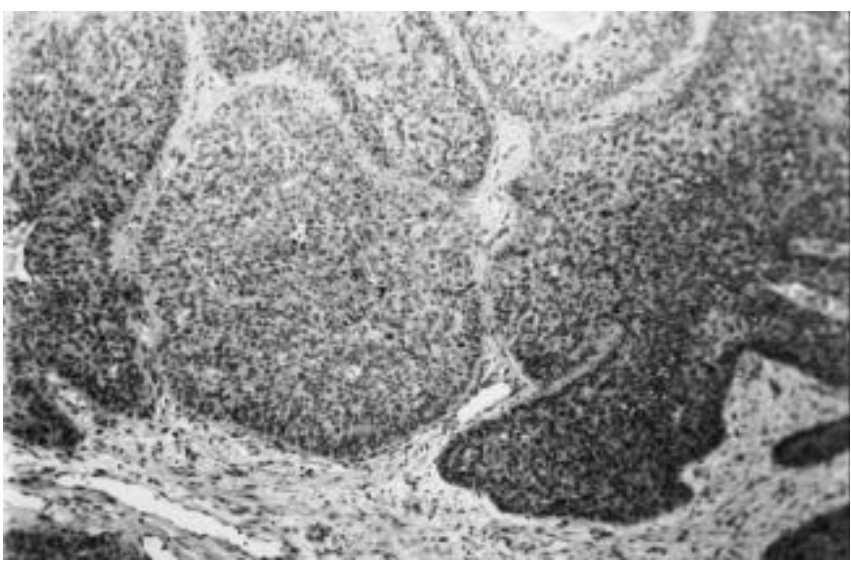

FIGURA 1 - Visão panorâmica de lesão com baixo escore de malignidade constituída por células epiteliais neoplásicas malignas formando margens bem definidas (H. E., $100 \mathrm{X})$.

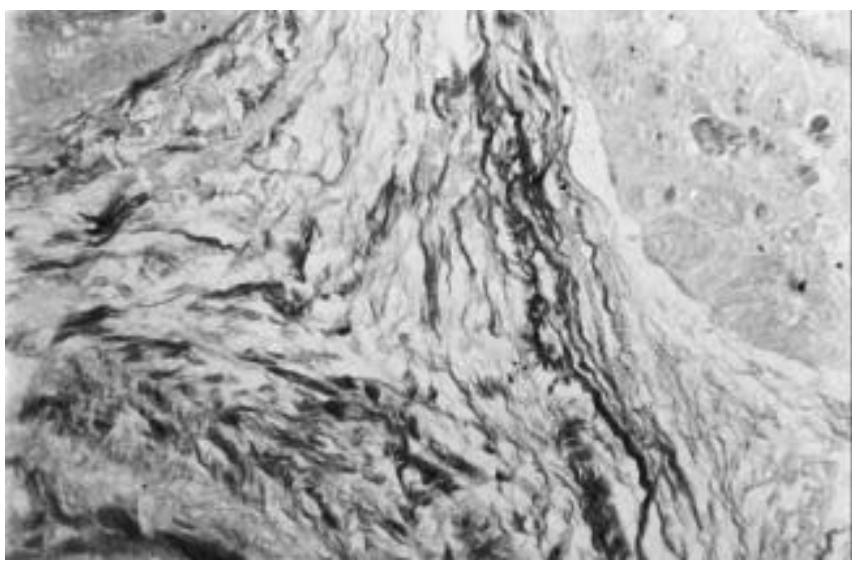

FIGURA 3 - Detalhe em lesão com baixo escore de malignidade dos feixes de fibras colágenas com disposição paralela intercaladas por células fusiformes na frente de invasão tumoral (picrosirius, $400 \mathrm{X}$ ).

sos $(22,2 \%)$ apresentaram número de mitoses acima de 5 por campo examinado. Individualmente as células tumorais exibiam ausência de ceratinização em 5 casos analisados $(55,5 \%)$ e mínima ceratinização nos casos restantes.

Quando se analisou o padrão de invasão, observou-se que a maioria das neoplasias era marcadamente difusa, com invasão de células isoladas ou em pequenos grupos (5 casos/55,5\%, Figura 4). Porém, quando esses achados foram confrontados com o restante das lesões do mesmo grupo de altos escores de malignidade, notou-se um padrão de invasão bem menos agressivo (4 casos/44,4\%).

A presença de infiltrado inflamatório foi escassa em 6 casos $(66,6 \%)$, tanto na área da invasão da

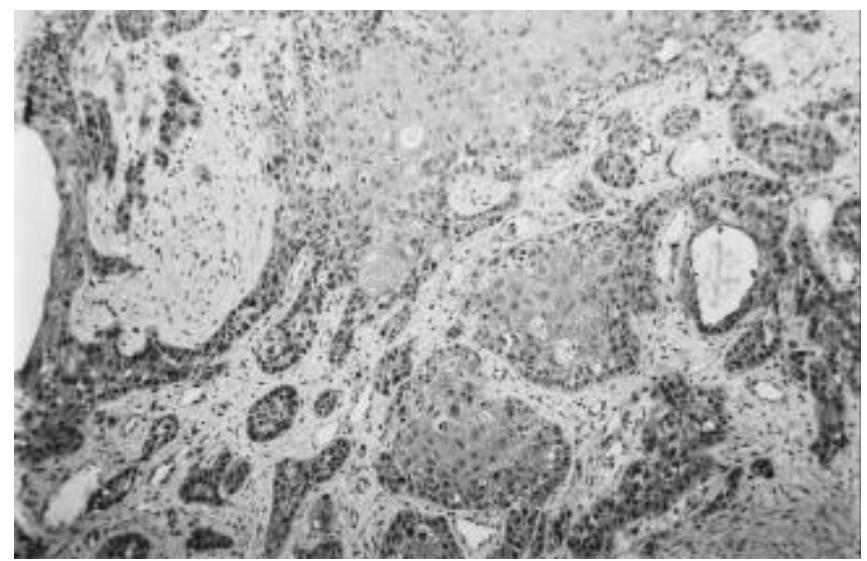

FIGURA 2 - Lesão de baixo escore de malignidade apresentando padrão de invasão mais agressivo, caracterizado, principalmente por lesões com grande contingente de células malignas formando pequenos cordões ou ilhotas (H. E., $100 \mathrm{X}$ ).

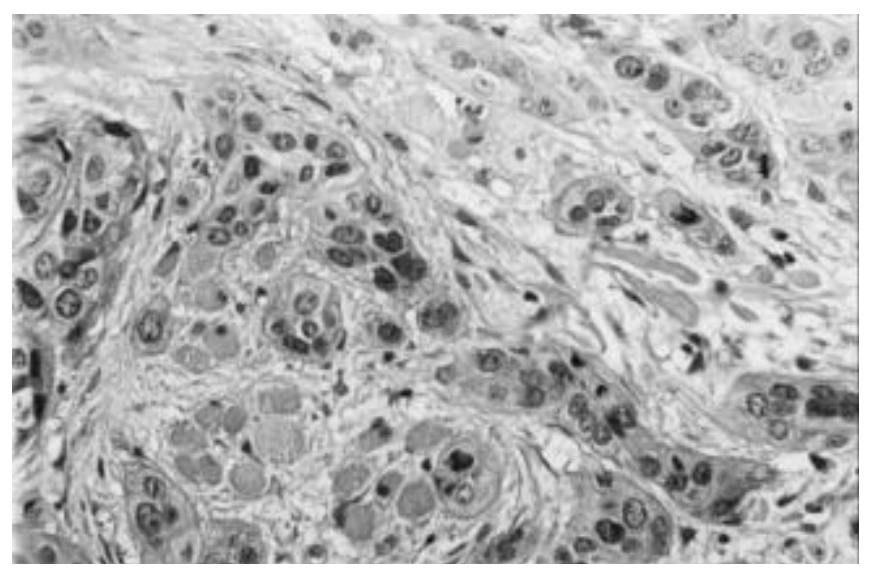

FIGURA 4 - Aspecto geral de neoplasia com alto escore de malignidade exibindo células epiteliais com núcleos hipercromáticos e padrão de invasão mais agressivo, constituido por ilhas que invadem o tecido conjuntivo (H. E., $400 \mathrm{X}$ ).

neoplasia como no restante do estroma e em 1 caso foi ausente. As células mais observadas foram os linfócitos e, muito raramente, plasmócitos.

A matriz extracelular mostrou nessas neoplasias menor nivel de sintese de colágeno, ao se estudar os cortes corados pelo picrosirius. Em algumas áreas, o colágeno teve um aspecto não-homogêneo, e as fibras apresentavam contornos pouco nítidos e finamente fibrilares (Figura 5). Os feixes mostravam-se irregulares, desorganizados e dissociados.

\section{Análise imuno-histoquímica}

A marcação imuno-histoquímica para o colágeno I foi observada no estroma de todos os casos de carcinomas epidermóides estudados. Nas lesões 


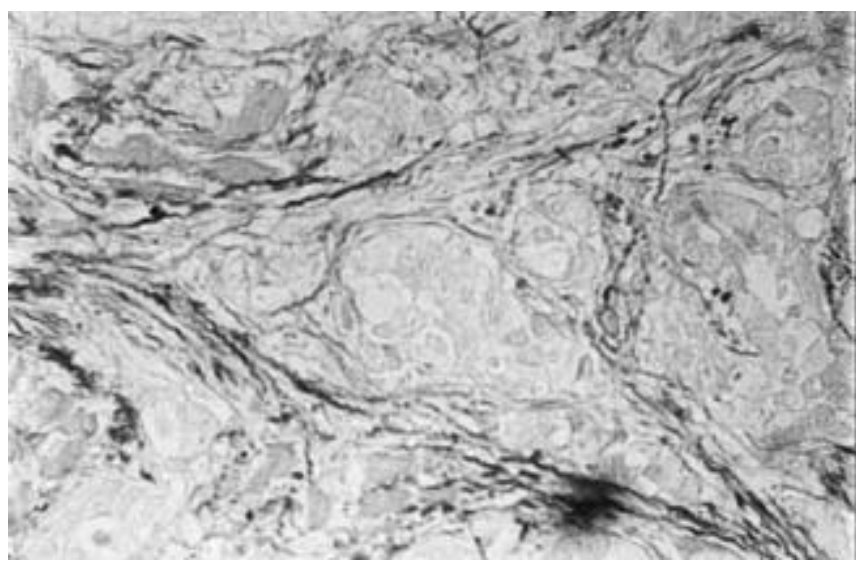

FIGURA 5 - Detalhe da matriz conjuntiva em lesão com alto escore de malignidade, observando o colágeno disposto em feixes mais finos e em algumas áreas descontínuos (picrosirius, $400 \mathrm{X}$ ).

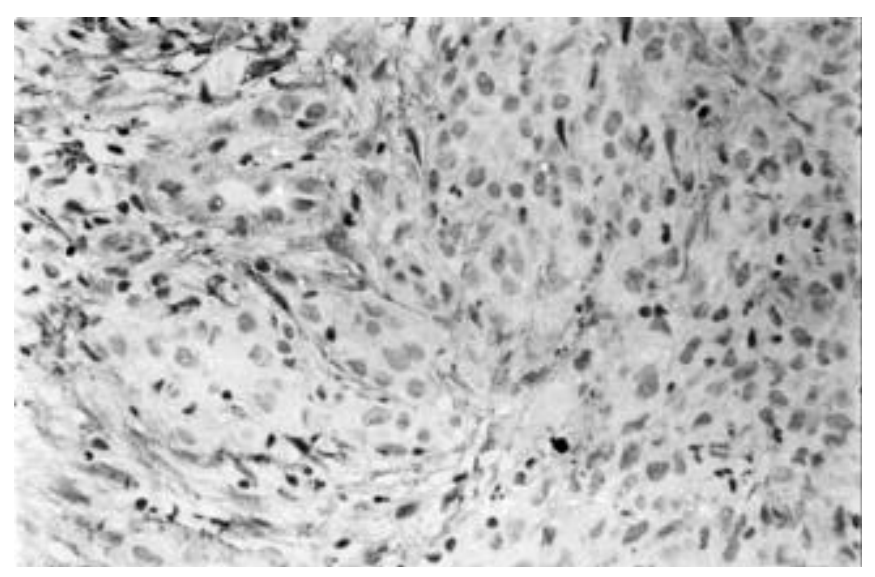

FIGURA 7 - Fraca marcação do colágeno I na frente de invasão de carcinoma com alto escore de malignidade (estreptavidina-biotina, $400 \mathrm{X}$ ).

com baixos escores de malignidade, este componente da matriz extracelular aparecia em toda a extensão do estroma, sendo expresso em fibras com feixes paralelos e algumas delas concêntricamente dispostas, exibindo um padrão moderado de marcação (Figura 6). Contudo, em 6 casos $(42,9 \%)$ deste grupo de lesões, notou-se uma tênue expressão do colágeno I apesar da matriz extracelular ter mantido o mesmo nível de organização das outras lesões. Nas regiões mais hialinizadas do tumor, o colágeno I mostrou-se mais organizado e melhor distribuído.

Nos carcinomas mais agressivos, caracterizados por altos escores de malignidade, o padrão de marcação foi distinto. O colágeno I foi expresso em feixes dissociados e muitas vezes fragmentados entre as células tumorais (Figura 7). Nestas lesões,

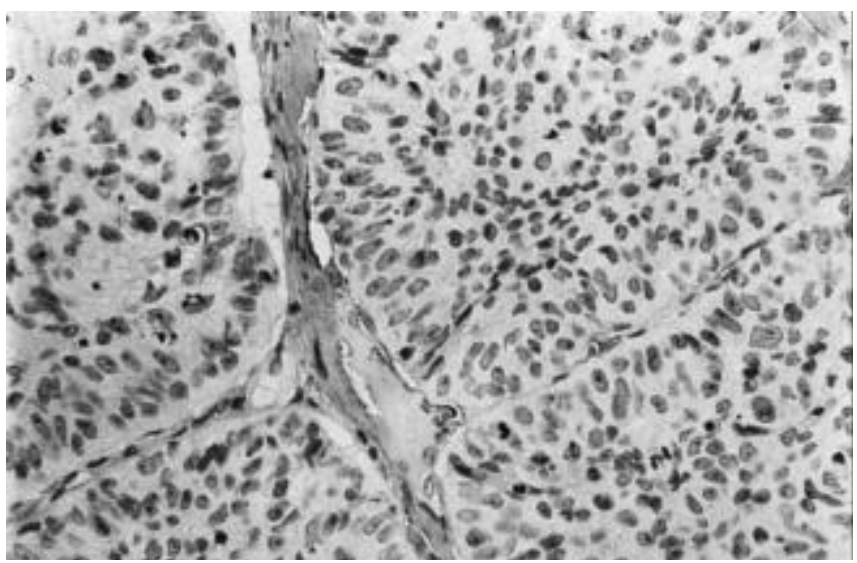

FIGURA 6 - Expressão moderada do colágeno I delimitando área de células tumorais, distribuídos em feixes organizados. Carcinoma epidermóide com baixo escore de malignidade (estreptavidina-biotina, $400 \mathrm{X}$ ).

a imunorreatividade do colágeno I foi menor na frente de invasão.

Nos casos estudados de carcinomas com baixos e altos escores de malignidade, não foi evidenciada reação imuno-histoquímica positiva para o anticorpo anticolágeno I nas células epiteliais malignas. A marcação foi limitada à matriz extracelular.

\section{DISCUSSÃO}

O carcinoma epidermóide é a neoplasia maligna mais freqüente da cavidade oral. O comportamento tumoral desta patologia parece ser influenciado tanto por suas características clínicas quanto por diferenças celulares e daí a necessidade sempre urgente de estudos cada vez mais aprofundados sobre esta patologia.

As pesquisas que tentam caracterizar o comportamento biológico do carcinoma epidermóide estão mais associadas aos aspectos morfológicos das células epiteliais malignas e menos freqüentemente se reportam às modificações que ocorrem no estroma tumoral induzidas pela invasão das células epiteliais. A frente de invasão tumoral é o local onde estes fenômenos acontecem com maior intensidade, uma vez que se trata da região que primeiro é acometida por estas alterações e que exibe a população de células neoplásicas mais agressivas $^{5,15,20}$. Além disso, é sabido, há anos, que os tumores pouco diferenciados, independentemente dos sítios de origem, são clinicamente mais agressivos que os bem diferenciados ${ }^{9}$. Um sistema de graduação histológica de malignidade que leve em consideração esses fatores deve ser visto como um importante auxiliar na determinação do prognóstico desta neoplasia. 
Martins GB, Reis SR de A, Silva TMC. Expressão do colágeno I em carcinomas epidermóides da cavidade oral. Pesqui Odontol Bras $2003 ; 17(1): 82-8$.

Não há ainda na literatura um consenso sobre o melhor sistema de graduação histológica a ser utilizado em pesquisas de carcinomas epidermóides da cavidade bucal ${ }^{6}$. Na rotina dos patologistas, o método preconizado por Broders ${ }^{4}$ (1941) é o mais utilizado. Este sistema analisa apenas uma das características morfológicas do tumor, a diferenciação celular. Faz-se, por isso, necessária a utilização de um sistema multifatorial para que diversos parâmetros morfológicos possam ser analisados e o real comportamento biológico individual de cada neoplasia identificado.

No nosso estudo foi utilizado o sistema de graduação histológica de malignidade preconizado por Anneroth et al. ${ }^{1}$ (1987) com a finalidade de diferenciar tumores mais invasivos daqueles considerados menos agressivos, o que serviu de referencial para as nossas observações. Verificou-se que dos 23 casos estudados, 14 pertenciam a carcinomas epidermóides com baixos escores de malignidade e 9 a lesões com altos escores de malignidade. Além disso, o estudo da região de invasão neoplásica preconizada por este sistema nos auxiliou no entendimento de outros parâmetros relacionados ao comportamento tumoral, como as modificações da matriz extracelular, especialmente a expressão diferenciada do colágeno I em lesões de altos e baixos escores de malignidade.

O estudo da matriz colagênica foi iniciado com a leitura das lâminas coradas pelo picrosirius. Por ser específico para colágeno, este método histoquímico evidenciou a característica fibrilar desta proteína e sua qualidade de apresentação nos diferentes escores histológicos de malignidade. Nos nossos achados, assim como nos de Zhu et al. ${ }^{24}$ (1995), que utilizaram técnicas imuno-histoquímicas em neoplasmas com maiores características de malignidade, o colágeno se apresentou como fibras delgadas, irregulares e pouco organizadas, particularmente circundando ilhas tumorais. Parecia haver maior intensidade de coloração em determinadas regiões enquanto outras áreas demonstravam degradação.

A análise dos casos considerados de altos escores de malignidade demonstrou menor reatividade para o anticorpo anticolágeno I quando comparados às lesões de baixos escores de malignidade. Essa observação reforça os achados de Kurahara et al. ${ }^{13}$ (1999) que observaram em investigações recentes em imuno-histoquímica que a redução da expressão de proteínas da matriz extracelular no carcinoma epidermóide está intimamente associada com o potencial de invasão e metástase. Kosmehl et al. ${ }^{12}$ (1999) complementam estes achados ao afirmarem que as moléculas presentes na matriz influenciam na diferenciação, proliferação, migração e possuem função de estabilização e separação.

Segundo Becker et al. ${ }^{3}$ (1993), na mucosa oral normal o que se observa é uma grande quantidade de colágeno tipo III na região subepitelial e os colágenos I e III nas porções mais profundas do tecido conjuntivo. No estroma dos carcinomas epidermóides da cavidade oral estudados, ao se observar o colágeno I através da imunomarcação com anticorpo específico, verificou-se que as fibras circundavam as ilhas epiteliais tumorais e se distribuiam por todo o estroma. Este achado confirma os estudos de Barsky et al. ${ }^{2}$ (1982), que observaram uma distribuição homogênea do colágeno tipo I, embora de forma difusa e pouco organizada nos carcinomas esquirróticos de mama.

No nosso trabalho, os 23 casos estudados apresentaram positividade para esta proteína, variando apenas a intensidade e qualidade de marcação. A coloração pelo picrosirius sugeriu algum tipo de modificação na arquitetura e distribuição das fibras colágenas, o que foi também visualizado através da imuno-histoquímica, uma vez que estas fibras passam de organizadas e continuas nos casos de carcinomas com baixos escores de malignidade para difusas e descontínuas nos casos com altos escores de malignidade. Esta informação é contrária às obtidas em carcinomas de ovário, onde todos os casos estudados demonstravam a mesma intensidade de marcação para o colágeno I, independente da graduação histológica ${ }^{18}$.

Na desmoplasia, apesar da alta deposição das fibras colágenas na frente de invasão tumoral, existe também um aumento da expressão de enzimas de degradação da matriz extracelular no estroma. Essas enzimas estão em altas concentrações próximas às células do estroma adjacente à invasão neoplásica. Este fenômeno foi interpretado como um dos eventos de proteólise nas regiões vizinhas do tumor que permitem o avanço das células neoplásicas. Entretanto, essas enzimas podem estar degradando apenas as proteínas recém-formadas da matriz pelas células do estroma ativadas pela invasão tumoral ${ }^{18}$. Embora nos estromas de carcinomas epidermóides da cavidade oral analisados houvesse produção de colágeno, o fenômeno da desmoplasia não foi um achado histológico observado, como ocorre nos tumores de ovário e do trato gastrointestinal, onde os colágenos I e o III são os mais encontrados ${ }^{18,23}$.

As pesquisas que visam compreender os processos de degradação da matriz extracelular com 
Martins GB, Reis SR de A, Silva TMC. Expressão do colágeno I em carcinomas epidermóides da cavidade oral. Pesqui Odontol Bras 2003;17(1):82-8.

certeza trarão informações importantes sobre o destino do colágeno nos tecidos neoplásicos, uma vez que parece indiscutivel em toda a literatura consultada que, a despeito desta proteína estar irregularmente distribuída nos tumores mais agressivos, ainda há formação intensa de fibras no estroma tumoral.

\section{CONCLUSÃO}

Baseado nos resultados obtidos concluímos que a matriz colagênica no estroma de carcinomas epidermóides da cavidade oral sofre modificações morfológicas e imuno-histoquímicas nos diferen-

\section{REFERÊNCIAS}

1. Anneroth G, Batsakis JG, Luna M. Review of the literature and a recommended system of malignancy grading in oral squamous cell carcinomas. Scand J Dent Res 1987; 95:229-49.

2. Barsky SH, Grotendorst GR, Liotta LA. Increased content of type $\mathrm{V}$ collagen in desmoplasia of human breast carcinoma. Am J Pathol 1982;108:276-83.

3. Becker J, Schuppan D, Müller S. Immunohistochemical distribution of collagens type I, III, IV and VI, of undulin and of tenascin in oral fibrous hyperplasia. J Oral Pathol Med 1993;22:463-7.

4. Broders AC. The microscopic grading of cancer. Surg Clin North Am 1941;21:947-62.

5. Bryne $M$. Is the invasive front of an oral carcinoma the most important area for prognostication? Oral Dis 1998;4:70-7.

6. Costa ALL, Toddai E, Araújo NS, et al. Otimização da técnica de dupla marcação PCNA/AgNOR em carcinoma epidermóide de boca. RPG 1998;5:177-83.

7. Cotran RS, Kumar V, Robbins SL. Pathologic basis of disease. $6^{\text {th }}$ ed. Philadelphia: Saunders; 2000.

8. Harada T, Shinoraha M, Nakamura S, Oka M. An immunohistochemical study of the extracellular matrix in oral squamous cell carcinoma and its association with invasive and metastatic potencial. Virchows Arch 1994; 424:257-66.

9. Henson DE. The histological grading of neoplasms. Arch Pathol Lab Med 1988;112:1091-96.

10. Imai Y, Sasaki T, Fujibayashi T. Volume-corrected mitotic index as a prognostic factor in oral squamous cell carcinomas. Oral Oncol 2001;37:72-4.

11. Junqueira LCU, Bignolas G, Brentani RR. Pricosirius staining plus polarization microscopy, a especific method for collagen detection in the tissue sections. Histochem $J$ 1979;11:447-54.

12. Kosmehl H, Berndt A, Strassburger S, Borsi L, Rouselle P, Mandel U, et al. Distribution of laminin and fibronectin isoforms in oral mucosa and oral squamous cell carcinoma. Br J Cancer 1999;81:1071-9.

13. Kurahara S, Shinahara M, Ikebe T, Nakamura S, Beppu M, Hiraki A, et al. Expression of MMPs, MT-MMP, and TIMPs tes escores histológicos de malignidade. O colágeno do tipo I foi observado em todas as lesões analisadas, mas sua presença é mais intensa nos tumores menos agressivos.

\section{AGRADECIMENTOS}

Ao Dr. Luís Antônio Rodrigues de Freitas, pesquisador titular do Laboratório de Patologia e Biologia Celular do Centro de Pesquisas Gonçalo Moniz (Fundação Oswaldo Cruz/Salvador - BA), por fornecer a estrutura necessária para a realização deste trabalho e por suas orientações sempre precisas.

in squamous cell carcinoma of the oral cavity: correlations with tumor invasion and metastasis. Head Neck 1999; 21:627-37.

14. Leong IT, Main JHP, Birt BD. Cancer of the tongue. J Can Dent Assoc 1995;61:792-6.

15. Lockhart PB, Norris Jr CM, Pulliam C. Dental factors in the genesis of squamous cell carcinoma of the oral cavity. Oral Oncol 1998;34:133-9.

16. McGaw WT, Pan JTH. Cancer of the gingival, buccal mucosa, and palate. J Can Dent Assoc 1996;62:146-50.

17. Mineta H, Miura K, Suzuki I, Takebayashi S, Amano H, Araki $\mathrm{K}$, et al. Low p27 expression correlates with poor prognosis for patients with oral tongue squamous cell carcinoma. Cancer 1999;85:1011-7.

18. Ohtani H, Kuroiwa A, Obinata M, Ooshima A, Nagura H. Identification of type I collagen-producing cells in human gastrointestinal carcinomas by non-radioactive in situ hybridization and immunoelectron microscopy. J Histoch Cytoch 1992;40:1139-46.

19. Oliver AJ, Helfrick JF, Gard D. Primary oral squamous cell carcinoma: a review of 92 cases. J Oral Maxillofac Surg 1996;54:949-54.

20. Piffkò J, Bànkfalvi À, Öfner D, Bryne M, Rasch D, Joos U, et al. Prognostic value of histobiological factors (malignancy grading and AgNOR content) assessed at the invasive tumour front of oral squamous cell carcinomas. Br J Cancer 1997;75:1543-46.

21. Raub MY, Dayan D. Polarization microscopy of picrosirius red stained sections: a useful method for qualitative evaluation of intestinal wall collagen. Histol Histopath 1994;9:525-8.

22. Ten Cate AR. Fibroblast and their products. In: Oral histology - development, structure, and function. $4^{\text {th }}$ ed. St. Louis: Mosby; 1994. p.81-99.

23. Tosios KI, Kapranos N, Papanicolau SI. Loss of basement membrane components laminin and type IV collagen parallels the progression of epithelial neoplasia. Histopath 1998;33:261-8.

24. Zhu GG, Risteli L, Mäkinen M, Risteli J, Kauppila A, Stenback F. Immunohistochemical study of type I collagen and type I pN-collagen in benign and malignant ovarian neoplasms. Cancer 1995;75:1010-7. 